О. В. Собакина

\title{
Сонорное направление и алеаторика
}

\section{в польской музыке. Сонорные фортепианные композиции Казимежа Сероцкого}

\begin{abstract}
Аннотация: польская музыка 196о-х г2. выделяется развитием экспериментальных направлений, среди которых наиболее ярким достижением стала сонористика. Особое место в развитии стилистики этого направления занимает творчество К. Сероцкого, фортепианные композици которого анализируются в данной статье. Тенденция развития сонорики оказалась наиболее устойчивой и перспективной, а открытый Сероцким звуковой мир с его собственной художественной проблематикой, пульсирующей драматургией эмоций остался по-прежнему актуальным. Именно эта сонорная основа дает возможности обогащения современного музыкального языка на основе взаимодействия с другими выразительными средствами. Новый красочный звуковой мир Сероцкого стал особым явлением современной музыки, открыл дорогу целому направлению, поскольку оказался не столько радикально новаторским, сколько богатым, воплотившим исключительную изобретательность и мастерство.

Ключевъе слова: искусствоведение, культура, искусство, польская музыка, творчество К. Сероцкого, сонорика, алеаторика, звуковой мир, современный музыкальный язык, композиторское мыциление.
\end{abstract}

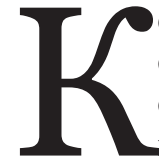

омпозиторское творчество 1960-х гг. представляется сложным и многообразным. С одной стороны, работали многие известные композиторы старшего поколения, с другой - композиторы, идущие новыми путями, далекими как от традиции, так и от радикального авангарда (среди них упомянем О. Мессиана, Д. Лигети, В. Лютославского, Э. Картера). Кроме того, расширялось движение авангарда, объединявшее композиторов, порвавших с традицией и ищущих новые способы «привлечения» слушателей. Факт резкого перелома композиторского мышления выразился в первую очередь в смелых поисках новых техник композиции.

Кризис сериализма, о котором писал Я. Ксенакис в 1955 г., направил некоторых композиторов к поискам новых основ формообразования, которые развивались в трех направлениях: максимальной «декомпозиции» музыкального произведения (алеаторика), математизации композиторской техники (стохастический метод Ксенакиса, компьютерная музыка) и экспериментов в области получения нового звучания. Алеаторика получила дальнейшее развитие в направлении регламентирования «случайности». В результате появилась особая форма, в которой автор регламентировал порядок монтажа звуковых структур 1 . Однако другой, более перспективной целью «монтажных» явлений был поиск развития новых сонорных форм. Электронные средства также были задействованы в этом процессе, но главный акцент был сделан на изобретении новых способов артикуляции и новых звучаний, заменивших бы ставшие обыденными мелодико-гармонические формы.

${ }^{1}$ Ю. М. Хоминьский называет ее «монтажной с регулируемой случайностью» (Chomiński J. M., Wilkowska-Chomińska K. Historia muzyki polskiej. Część II. Kraków: PWM, 1996. S. 166).
Термин «сонористика» (мы опираемся на принятое в отечественном музыкознании понятие «сонорика» Ю. Холопова) был введен Ю. М. Хоминьским в 1956 г., но только к 1990 г. видный польский теоретик представил заново упорядоченный им состав средств, который, по его мнению, способствует возникновению «чистого звучания ${ }^{2}$. К ним относятся: нивелирование первостепенного значения мелодического, а также монохронического управления временем; расширение звукового пространства путем включения «открытых» систем, что влечет подключение всего 12-тонового строя равномерно по всей вертикали в плане организации состава звукового материала; принятие полихронии как основной организации управления временем, благодаря чему темп и метр оперируют мобильными временными характеристиками; новые звуковые характеристики (претворение отзвуков, равноценность тонов и шумов; изоляция звуковых импульсов в разных высотных областях и разных динамических уровнях).

Однако главным характерным сонорным качеством становится красочная сторона звучания, связанная с источником звука или выбором исходного материала. Ритм, гармонический состав, динамика, артикуляция также могут способствовать созданию сонорных «красочных» качеств, в том числе благодаря вариативной моторике, изобретению новых способов артикуляции, включению препарированных инструментов, а также электроники, использованию кластеров и четвертитоновых рядов.

Форма в сонорных композициях опирается на специальную для каждого сочинения систему пра-

${ }^{2}$ Chomiński J. M. Historia harmonii i kontrapunktu. T. 3. Kraków, 1990. S. 555. 
вил и проявляется во взаимодействии определенных элементов. Определяющей характерной чертой сонорной техники стала формообразующая роль звука как краски и повышенное внимание к регуляции динамики. В числе характерных особенностей динамики в сонорной композиции, исходя из классификации Хоминьского, прежде всего упомянем изменение равновесия в аккордовых вертикалях 3 .

В области временно́й организации композиции также можно отметить ряд характерных особенностей. В целом отличительными особенностями регуляции времени стали монохрония и полихрония. Монохрония, связанная с традицией, опирается на четко обозначенные метрические единицы ритмического движения, подчиненные определенности тактовых структур. Полихрония, напротив, противоречит традиционным ритмическим основам, опираясь на свободное течение динамичных звуковых импульсов. Представляет интерес процесс эволюции, выявляющий пути развития полихронии в польской музыке. Эта техника была преобразованием ритмических импульсов в нераздельную звуковую массу вплоть до потери метрической регуляции. В наиболее сложных структурах сочинений конца 1950-х гг. моторного характера ослабла или вообще исчезла ритмическая определенность. Свободные, воспринимаемые элементарно временные границы сочинения согласовывались с концепцией монолитного временного континуума, аналогичного природному. Одновременно такой континуум имел свою внутреннюю процессуальность, выражающуюся в определенной иерархии активности смен звуковых комплексов.

Это и привело к изменению подхода ко всему объему ритмических проблем и появлению новых основ регуляции времени. Точкой их отсчета стал синтез двух элементов: ритма и агогики. В некоторых произведениях выявлялись явные фазовые агогические смены, приводящие к преобразованию ритмических импульсов, особенно в случае использования композитором новых выразительных средств. Важным фактором, повлиявшим на формировании полихронии, стало формирование стабильных звуковых структур (континуумов), противоречащих фиксированности ритмики и усложнивших метрический склад 4 .

Полихронию широко использовали композиторы польского музыкального авангарда: В. Лютославский, К. Сероцкий, К. Пендерецкий, Х. М. Гурецкий, В. Киляр, Б. Шеффер, В. Котоньский, Т. Сикорский. В первое

\footnotetext{
3 Самое раннее разграничение динамики в аккордовых вертикалях в польской музыке использовал А. Пануфник в фортепианном цикле «Квинтовый круг».

${ }^{4}$ Chomiński J.M., Wilkowska-Chomińska K. Historia muzyki polskiej. Część II. S. 164.
}

время полихрония имела алеаторический характер и была скорее спонтанным явлением. На первый взгляд может показаться, что полихрония предоставляет исполнителю свободу и предполагает спонтанность звуковых событий во времени. Однако в действительности регулирование времени в этой системе подчинено гораздо большей дисциплине, чем ранее, поскольку движение спонтанных на слух звуковых импульсов точно определено во времени. Столкновение двух типов организации времени - монохронии и полихронии - находит выражение в сложной ритмической структуре композиции, когда временной тип не проявлен в ее начале и формируется в процессе развертывания (как в «Венецианских играх», 1961 г., Лютославского). Сонорное направление быстро утратило привкус сенсационности, поскольку аналогичные поиски в европейской музыке наблюдались уже давно. И если эти поиски вначале шокировали, то затем оказалось, что именно в них кроются огромные возможности, что показал своим творчеством К. Сероцкий.

Основным направлением творчества Казимежа Сероцкого (1922-1981) стал поиск новых звуковых качеств, новых способов использования традиционных инструментов. Именно в этом русле он осуществил масштабные преобразования звуковой техники, оправдавшие его славу как одного из самых выдающихся композиторов-сонористов. В рамках сонорной эстетики Сероцкий оставался два десятилетия: с 1960-х гг. до конца своей жизни. В противовес сериализму Ноно и Штокхаузена и алеаторике Кейджа Сероцкий в начале 1960-х гг. представил свою концепцию авангардного сочинения, прочно связанного с идеей обновления современной музыки и, соответственно, не использующего старые модели и выразительные средства. Ему оставался лишь один путь обновления исходной субстанции музыки - звучания, получения его новых характеристик, красок, форм движения. В результате Сероцкий стал не только одним из вдохновителей сонорного направления (наряду с Пендерецким), но и композитором, художественное кредо которого выделялось среди его молодых коллег.

Прежде всего, Сероцкий не имел целью «сенсационное» обновление трактовки инструментов и построение звуковых конструкций из «немузыкальных» источников звука, а также из субтильных «шорохов» (вспомним «Трен» Пендерецкого). Он использовал широкую палитру звуковых красок, строя из нее новую, целостную звуковую поэтику, а необычные звуковые краски и артикуляционные приемы применял выборочно, в целях достижения определенного конечного результата. Самые смелые его открытия приходятся на более поздние годы, когда новые средства выразительности уже воспринимались как естественный способ обогащения 


\section{Культура и искусство 3(9) • 2012}

имеющихся средств. Не привлекали Сероцкого и виды новых, стилистически простых конструкций, простые звуковые формы типа кластеров, тремоландо, изменения плотности звучания.

Вступая на свою дорогу, Сероцкий предстал максималистом: по его мнению, новая музыка должна быть игрой элементов, отличающихся богатыми звуковыми характеристиками и выразительностью избранных звуковых качеств, и, что главное, она должна создавать не менее сложные и драматургически цельные формы! Свою задачу композитор видел в использовании известных форм, опирающихся при этом на иную звуковую субстанцию. В соответствии с этой позицией главной особенностью композиций Сероцкого стал радикальный перенос структурирующего акцента на звучание и его автономные свойства в области красочности, формы и движения. Эта позиция тем более поразительна, что в раннем творчестве Сероцкий проявлял редкую мелодическую изобретательность. В его же «авангардном» творчестве основную драматургическую роль в построении системы выразительности и формообразования получило звучание как таковое.

Значит ли это, что Сероцкий раз и навсегда отказался от мелодических выразительных возможностей? Их он использовал в позднем творчестве выборочно, поскольку его слишком увлекла возможность богатых манипуляций звучанием, перспектива экспериментов с новыми трактовками инструментов, которые в его сочинениях не шокировали слушателей, а демонстрировали новые ценные краски, служили определенным выразительным эффектам. Сероцкий остался непревзойденным мастером в этой области, он был скорее новатором, чем просто ищущим авангардистом.

В области организации времени Сероцкий также выработал собственную систему. Его композиции организованы особым метроритмом, образованным рядом импульсов, определяемых сменами красок и типов движения, знаков динамики, качествами фактуры. Он компонует произведение из отличных, остро характерных типов движения. Частота их смен выражает динамику развития, а интенсивность движения, подчиненная образной концепции, определяет размеры композиции. Как правило, произведения Сероцкого отличаются удивительно стабильной продолжительностью - 12 минут; минимальным размером выделяется «Swinging Music», а максимальным (16 минут) - подчиненное литературным инспирациям «Dramatic Story».

Система формообразования Сероцкого после начала 1960-х гг. подчинена двум концепциям: модели и музыкального характера. Модели - это элементарные части композиции, которые очерчивают ма- териал, регулируют соотношения ритма, фактуры и вертикали (как правило, 12-тоновой). Они становятся основой многосоставной целостности, и форма в этом случае предстает процессом, выражающимся в прохождении через ряд фаз развития. Особенностью развития формы часто становятся линеарные структуры (порой типа виртуозных каденций, как в «Forte e piano», «Fantasia elegiaca»), определяющие начало фаз развития и заключительный фрагмент. Отдельные партии инструментов поочередно вступают и накладываются друг на друга по аналогии с полифонической экспозицией. Создаваемая ими плотная фактура образует в партитурах сочинений один пласт, подобный «звуковой магме». Не случайно Сероцкий предпочитал писать композиции для ансамблей, прежде всего с участием фортепиано: в его зрелом творчестве фортепиано всегда предстает в окружении других инструментов.

Модели в записи обычно предстают в виде «отрезков» сочинения, отделенных специальной записью, часто ярко выраженного графического характера и определенной временной протяженности. Избранный материал композитор распределяет на различные выразительные группы, где все параметры исполнения вписаны им: состав исполнителей, средства инструментов, тип структур, динамика, время и порядок вступления, паузы между ними. В результате появляется ряд «запланированных» кульминаций, делящих композицию на ряд фаз развития и приводящих к заключительной кульминации.

Другим существенным для Сероцкого типом формообразования стала техника монтажа развития из коротких, различающихся по движению и краске звеньев, которую он применял на разных этапах формы. Обе техники формообразования выражают основные диалектически связанные стороны процесса композиции - целостности и изменчивости процесса развития, и взаимодействие этих сторон влечет трансформацию элементов на основе избранной организации времени. Таким образом, можно отметить присутствие определенного конструктивизма в творческом методе Сероцкого. Попутно отметим, что композитор преимущественно использовал замкнутые формы, одно- или многочастные с выразительной кульминационной зоной; «открытую форму» представляют только две композиции - «Ad libitum» и «A piacere».

Однако вернемся в сферу фортепианной музыки. Несмотря на открытие новых тембровых горизонтов, она по-прежнему была лабораторией композиторского творчества. И важно отметить, что в этой области Сероцкий был одним из наиболее компетентных композиторов, а кроме того, фортепиано его постоянно привлекало! Первым сочинением, в котором он продемонстрировал свою новую технику, стали две композиции для ансамблей - «Эпизоды» и «Сегменты», затем была на- 
Музыка и музыкальная культура

писана фортепианная пьеса «А piacere» (1963)5. Как писал в статье по поводу премьеры этого сочинения известный музыковед Т. А. Зелиньский, «не стремясь к таким эффектам, как препарирование инструмента, извлечение звука из струн и т. п., и ограничиваясь только традиционным использованием клавиш, композитор смог создать богатый, разнообразный звуковой материал...»6

В композиции исполнителю предложены 30 мотивных структур, уложенных по 10 в трех сегментах. Из этих структур, длящихся определенное количество секунд, пианист создает форму по своему усмотрению, поскольку порядок исполнения структур не зафиксирован; однако он не может ни пропустить, ни повторить ни одну из них. Аналогичная форма использована в композиции для оркестра из пяти частей «Ad libitum» (1977).

Концепция подобных форм вариативна, однако в структурах «A piacere» можно найти много интересных идей, направленных на создание замкнутой целостности. Теоретически концепция сочинения не исключает функций формы - все зависит от того, каким в эстетическом и эмоциональном свете «услышит» произведение исполнитель, а затем и слушатель. Тем не менее разнородность структур, имеющих индивидуальный колорит, разделенность их паузами говорят о том, что все-таки добиться какой-либо целостности в таких композициях практически невозможно.

Трудность исполнения подобного сочинения заключается не столько в образовании этой целостности, сколько в организации драматургии развития во время исполнения, которое продолжается от 6 до 8 минут. Не просто для пианиста и распределить структуры в обозначенных композитором временных границах. Подобные «открытые монтажные формы» оказываются слишком неординарными для исполнителя, поскольку имеют неограниченное число исполнительских версий одного сочинения.

Однако ситуация изменяется, если рассматривать структуры как замкнутые целостности, поскольку они, независимо от своих размеров, заключают много интересных идей. Их можно даже сопоставить с системой лейтмотивов, где каждый отождествляется с выразительной музыкальной мыслью (и даже микромыслью). Всю композицию можно рассматривать как сюиту из исключительно емких миниатюрафоризмов (т. е. звуковых структур). Каждая структура, независимо от степени сложности, представляет индивидуальную концепцию и становится в определенном смысле автономной микрокомпозицией.
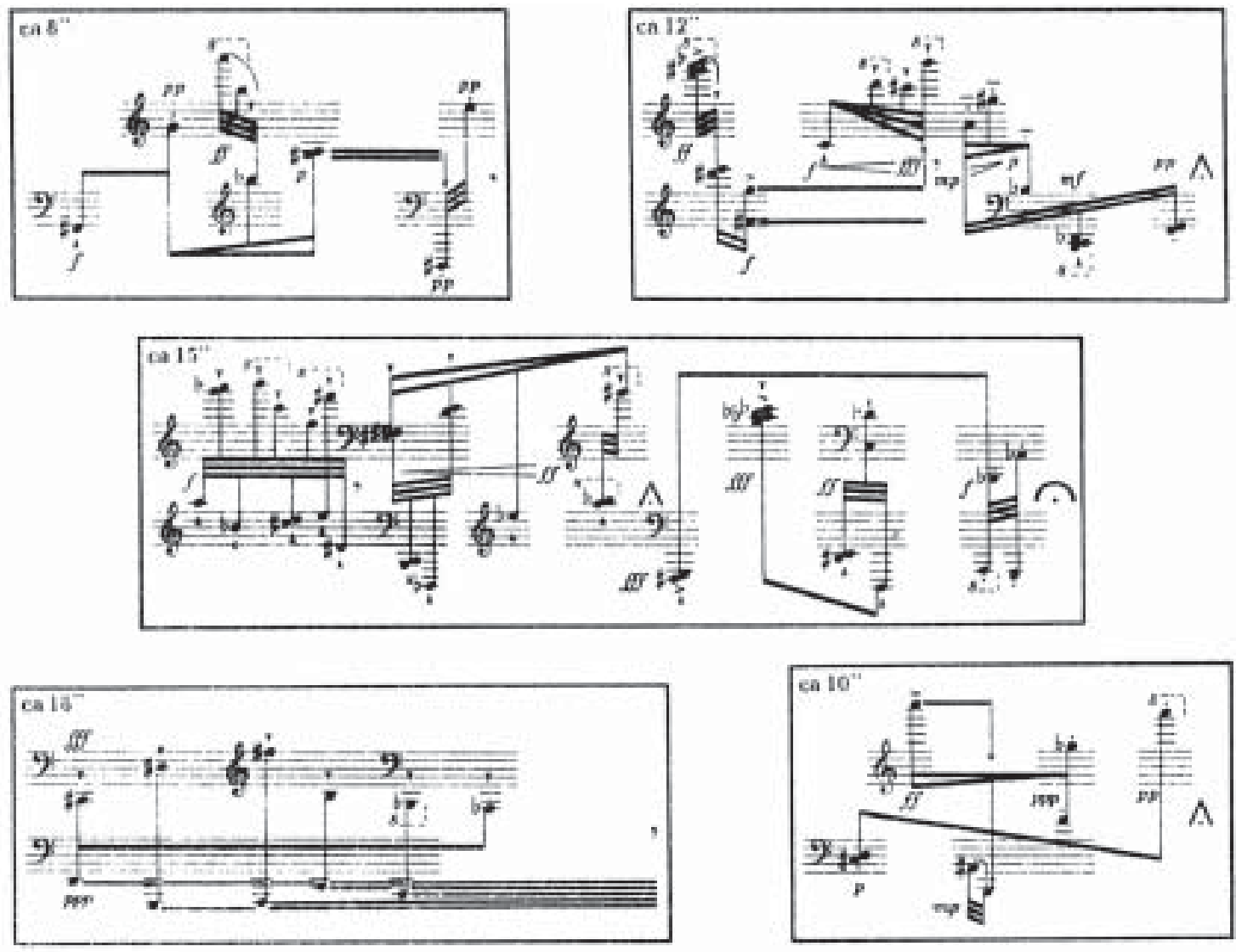

5 Вспомним, что к этому времени уже были написаны «Сюита прелюдий» и «Соната».

${ }^{6}$ Zieliński T. A. «A piacere» Kazimierza Serockiego // Ruch muzyczny, 1963. № 22. S. 17.

Рис.: К. Сероцкий. A piacere (фрагмент первого сегмента). 


\section{Культура и искусство 3(9) • 2012}

Как уже было упомянуто, все композиции Сероцкого отмечены структурообразующими качествами, и поэтому «А piacere» представляет в творчестве композитора экстремальную форму, аналог которой можно увидеть в ранее написанной «Klavierstück IX» Штокхаузена. Демонстрируемый Сероцким метод композиции связан с его собственной концепцией выразительных качеств, а именно «музыкальных характеров»7. В «А piacere» каждый из трех сегментов представляет индивидуальный характер, определяемый через общий для его структур ряд фактурных и агогических свойств. Материал первого сегмента опирается на раздельность звуков, редко образующих какие-либо группы (около 15 \%). Контуры фактуры обрисованы скачками на широкие интервалы, контрастами регистров. Разреженность и контрастность подчеркнуты артикуляцией и динамикой. Интересно, что педаль в первом сегменте композитор использует лишь дважды, а все окончания структур острые. Значительно свободнее и спокойнее по характеру средний сегмент. Здесь также используются одиночные звуки, но они интенсивнее стремятся в группы созвучий, а артикуляция основана на деликатном стаккато. Все структуры сопровождаются богатой педализацией, паузы сопровождаются отзвуками, что дает совершенно иной тип контраста. В заключительном сегменте доминирует аккордика, организуемая разнообразными ритмическими импульсами. Энергия и динамика смен структур подчеркнута их монолитностью. Как видим, образные характеристики предусмотрены композитором, и общий эмоциональный колорит практически независим от настроения исполнителя.

«A piacere» является интереснейшим «каталогом» современных фортепианных звучаний и пианистических форм. Ограничиваясь традиционным способом игры на инструменте, композитор создал богатый красками, разнообразный звуковой материал, в котором представлены различные способы артикуляции, тончайшие динамические нюансы, подчеркнутые использованием педалей. Во всем этом проявляется великолепное знание специфики инструмента и его сонорных возможностей, а также понимание ответственности композитора за эстетические эффекты создаваемых звуковых структур.

В целом в сонорной музыке развивались различные формы, которые можно объединить в два направления: традиционное и технократическое. Первое использовало возможности естественных музыкальных объектов, т. е. голоса, инструмента, иных источников; второе - электронных средств.

\footnotetext{
7 Наибольшую степень взаимосвязи концепции музыкальных характеров и техники структур, по существу являющейся техникой моделирования, представляет «Dramatic Story».
}

Электронные средства значительно упростили оперирование разными категориями звучания, так как позволяли осуществлять разного рода звуковые перевоплощения и давали принципиально новые возможности развития звукового материала. Одной из первых попыток использования электроники в формировании произведения крупной формы стала симфония «Muzyka elektroniczna» Б. Шеффера («Электронная музыка», 1966). Композиции, в которых традиционные инструменты выполняли сонорные функции, получили значительно бо́льшую популярность. В поисках новых звучаний использовались прежде всего ударные инструменты, значение и количество которых непомерно возросло, а также фортепиано.

Главные конструктивные задачи, стоящие перед композиторами в условиях новой техники композиции, были связаны с отбором средств и возможностями преобразования звукового материала, почерпнутого из разнородных источников звучания. Подключение электронных средств на сцене в процессе исполнения позволяло осуществлять разного рода звуковые перевоплощения, что давало принципиально новые возможности развития звукового материала. Новые техники изменили саму эстетику творчества, которое стало апеллировать к игре как смыслу творчества. Именно отсюда идут линии к новым техническим приемам, связанным прежде всего с алеаторикой, а также к появлению новых форм и жанров.

Вот как систематизирует видный польский музыковед Б. Поцей линии развития алеаторики в статье «Источники алеаторики. III. Игра». Самые простые «классические» примеры - в духе игры в кости, примером может послужить «А piacere» Сероцкого.

Неполная обозначенность избраннъх элементарньх качеств, как, например, в фортепианных сочинениях Б. Шеффера: «Здесь мы имеем точно заданные точки отсчета и обозначенные правила игры, а также строгое разграничение между тем, что уже дано, и тем, что может быть. Например, в Studium $w$ diagramie даны интервалы и виды возможных структур [...], не обозначены и вариантны ритм и звуковой материал». Интересен вывод польского ученого: «В игре элементарных качеств шансы исполнителя - главного партнера, разыгрывающего текст, - значительно выше, чем в “сегментовой” игре; его роль значительно более творческая, а количество возможных версий композиции - “пунктов прибытия" - несравнимо болыше» .

Инструментальнй театр - игра чистого смысла. «Тут речь идет о демонстрации, презентации - в смысле аудиовизуальном - рождающейся музыки, творимой музыкантами в процессе, которым руководит специальный координатор».

${ }^{8}$ Pociej B. Żródła aleatorismu. III. Gra // Ruch muzyczny. 1966. № 20. S. 2. 
Формъц «эссенциальной» алеаторики, т. е. предложения и впечатления, полученные от знакомства с графикой или текстом и дающие импульс воображению исполнителя (развиваемые Кейджем, Буссотти, Шеффером).

Тотальная алеаторическая игра, так назъєваемый happening. Это игра как таковая, без какой-либо цели, апогей идей алеаторики.

Вывод Б. Поцея более чем правомерен: «Алеаторика, доведенная до крайности, оказывается своего рода “игрой с бесконечностью”»9.

В этой игре для композиторов важной стала эстетика декомпозиции, когда идеей сочинения становится инверсия процесса. Таким образом появляются «открытые формы», «мобильные формы», а также никак специально не обозначенные формы. Әстетика декомпозиции стала способом создания новой композиции, а не противопоставления авангардного сочинения традиционным нормам; о типе экспериментального метода часто заявляет название композиции («Open music», «Negative music» Б. Шеффера - для любых инструментов!).

Уже в конце 1960-х гг. сформировалась ситуация, в которой авангардные эксперименты перестали быть актом какой-либо творческой смелости и появилось осознание того, что радикальный разрыв с традицией перешел все мыслимые границы. Многие композиторы стали пересматривать свое отношение к идеям авангарда и искать иные способы выражения своей индивидуальности. В тот же период появляются и первые признаки реакции на авангард; известные композиторы пытаются найти в традиционных средствах новый, неизвестный до сих пор смысл и выразительность (достаточно упомянуть минимализм). В 1970-е гг. появляется волна композиций, основанных на принципах, вызывавших ранее протест у композиторов: романтических мелодико-звуковых построений, простейших консонансов, обычных тонально-гармонических отношений и простых эмоционально-структурных идей.

Однако тенденция развития сонорики оказалась наиболее устойчивой и перспективной. Не случайно Сероцкий негативно воспринял реакцию на эксперимент: он считал, что возвращение к прошлому не дает перспективы развития, и открытый им мир с его собственной художественной проблематикой, пульсирующей драматургией эмоций по-прежнему актуален. Стиль Сероцкого доказал свою самоценность и уже не зависел от модных тенденций, более того, именно в этот период композитор подтвердил положение о том, что основным элементом современной музыки должен быть звук. Именно эта сонорная основа дает возможности обогащения со-

${ }_{9}^{9}$ Pociej B. Żródła aleatorismu. III. Gra. S. 3. временного музыкального языка на основе взаимодействия с другими выразительными средствами.

В 1970-е гг. Сероцкий вступил в новую фазу развития своей звуковой поэтики. Среди крупных сочинений выделяются «Фантасмагория для фортепиано и ударных» (1971) и «Swinging Music» с участием приготовленного фортепиано (1970). В этих композициях каждое мгновение поражает новой необычной краской. Характерно, что композитор стремился раскрыть возможности фортепиано в сопоставлении с различными составами. Неслучайно ранее он написал «Концерт для двух роялей с оркестром», посвященный знаменитому дуэту из ФРГ Альфонсу и Алоизу Контарским (1967). Концертные опусы Сероцкого отличаются динамикой и энергией движения, контрастными сопоставлениями изысканных импрессионистских фактур с эффектной ударной моторикой.

Два последних сочинения Сероцкого стали убедительным подтверждением его творческого кредо. «Ad libitum» для оркестра, упомянутый ранее, и «Pianophonie» продемонстрировали дальнейшее развитие творческого метода композитора. Трансформации исполняемого на сцене звукового материала с помощью специальной аппаратуры в процессе исполнения Сероцкий использовал в «Pianophonie» (1976-1978) для фортепиано, оркестра и электронной трансформации звука. Это - последнее сочинение композитора, в котором он подытожил многолетние творческие поиски. В нем проясняются мелодические контуры, особенно в медленных эпизодах (появляются характерные мотивы), рельефнее прочерчена фактура благодаря отбору и определенным соотношениям интервального состава структур. Определенный поворот к тематизму и гармонии значительно обогатил состав аккордики, однако частичное обращение к традиции сочетается здесь с дальнейшими поисками в сфере сонорики.

Только в «Pianophonie» Сероцкий прибег к приемам так называемой «live electronic music», подразумевающим непосредственное участие электронных средств в процессе исполнения. Электронные преобразования звучания фортепиано в сочетании с непосредственным звучанием инструмента и использованием многообразия ударных инструментов дали новые возможности сонорного обогащения фортепианных композиций. Возможно, это сочинение могло бы стать началом нового этапа творчества Сероцкого, упоминавшего в последние годы о том, что он вынашивает идею «решительно мелодического» сочинения и стремится к синтезу «красочной» и «мелодико-гармонической» музыки.

Творчество Сероцкого после 1960 г. объединяет цельный индивидуальный стиль, который узнаваем практически после первых же секунд звучания сочинения (прежде всего - по типу движения звуковых 
структур). Оригинальность его творческого мышления заключается в уникальной тембровой фантазии, в умении открыть в инструментах новые звучания, поражающие необычной красотой, что придает его творчеству болышую эстетическую ценность. Произведения Сероцкого - яркие и динамичные абстрактные полотна, увлекающие слушателя феерией красок. Однако композитора по праву можно считать мастером не только краски, но и организации звукового пространства и времени. Не случайно его почерк отличает редкая динамичность и оригинальность фактуры.

Новый красочный звуковой мир Сероцкого стал особым явлением современной музыки, открыл дорогу целому направлению, поскольку оказался не столько радикально новаторским, сколько богатым, воплотившим исключительную изобретательность и мастерство. Новые средства, примененные им, смогли стать основой новой, яркой эмоциональной выразительности, позволяющей говорить о ее особой экспрессии. Огромное разнообразие образов Сероцкого удивляет: он практически не повторял себя! Независимо от дальнейших намерений мастера, богатый опыт его творчества, связанный с новой эстетикой звучания, стал самостоятельной ценностью польской музыки и наследием, вдохновлявшим других композиторов.

\section{Список литературы:}

1. Chomiński J. M. Historia harmonii i kontrapunktu. T. 3. Kraków, 1990.

2. Chomiński J. M., Wilkowska-Chomińska K. Historia muzyki polskiej. Część II. Kraków, 1996.

3. Pociej B. Żródła aleatorismu. III. Gra // Ruch muzyczny. 1966. № 20.

4. Zieliński T. A. «A piacere» Kazimierza Serockiego // Ruch muzyczny. 1963. № 22.

\section{References (transliteration):}

1. Chomiński J. M. Historia harmonii i kontrapunktu. T. 3. Kraków, 1990.

2. Chomiński J. M., Wilkowska-Chomińska K. Historia muzyki polskiej. Część II. Kraków, 1996.

3. Pociej B. Żródła aleatorismu. III. Gra // Ruch muzyczny. 1966. № 20.

4. Zieliński T. A. «A piacere» Kazimierza Serockiego // Ruch muzyczny. 1963. № 22. 